ARMy Research Laboratory

ARMY RESEARCH LAB

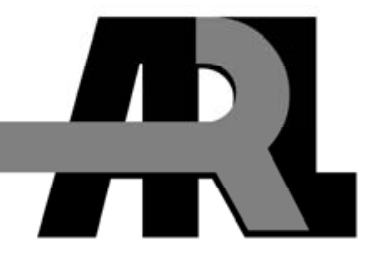

\title{
Demonstration of Ethanol and JP-8 Fuel Atomization Using Micromachined Silicon Multiplexed Electrosprays
}

\author{
by Israel Boniche and C. Mike Waits
}

ARL-TR-4816

May 2009

Approved for public release; distribution unlimited. 


\section{NOTICES}

\section{Disclaimers}

The findings in this report are not to be construed as an official Department of the Army position unless so designated by other authorized documents.

Citation of manufacturer's or trade names does not constitute an official endorsement or approval of the use thereof.

Destroy this report when it is no longer needed. Do not return it to the originator. 


\section{Army Research Laboratory}

Adelphi, MD 20783-1197

\section{Demonstration of Ethanol and JP-8 Fuel Atomization Using Micromachined Silicon Multiplexed Electrosprays}

Israel Boniche and C. Mike Waits

Sensors and Electron Devices Directorate, ARL 
Public reporting burden for this collection of information is estimated to average 1 hour per response, including the time for reviewing instructions, searching existing data sources, gathering and maintaining the data needed, and completing and reviewing the collection information. Send comments regarding this burden estimate or any other aspect of this collection of information, including suggestions for reducing the burden, to Department of Defense, Washington Headquarters Services, Directorate for Information Operations and Reports (0704-0188), 1215 Jefferson Davis Highway, Suite 1204, Arlington, VA 22202-4302. Respondents should be aware that notwithstanding any other provision of law, no person shall be subject to any penalty for failing to comply with a collection of information if it does not display a currently valid OMB control number.

PLEASE DO NOT RETURN YOUR FORM TO THE ABOVE ADDRESS.

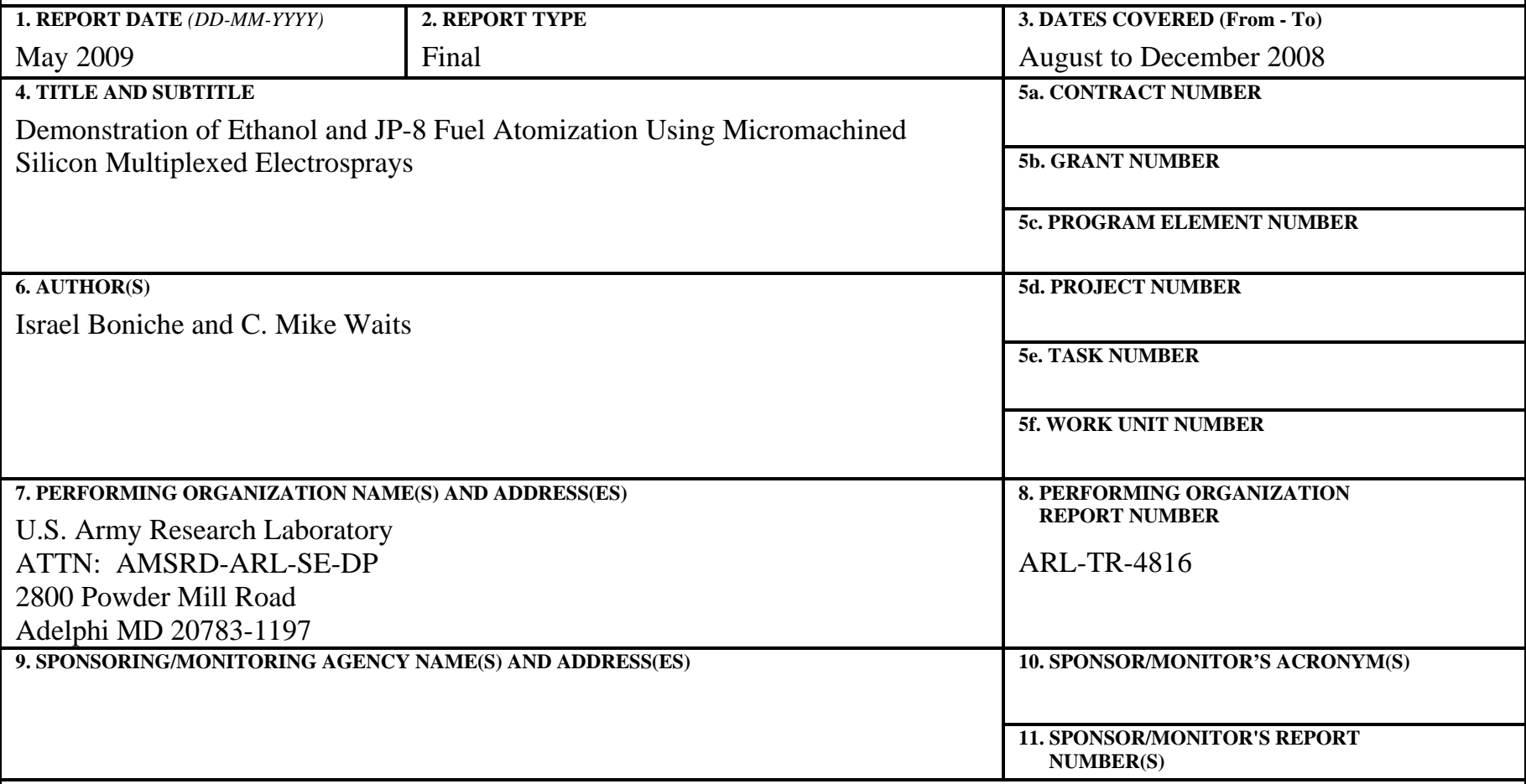

12. DISTRIBUTION/AVAILABILITY STATEMENT

Approved for public release; distribution unlimited.

\section{SUPPLEMENTARY NOTES}

\section{ABSTRACT}

This work discusses the fabrication and experimental testing of multiplexed electrospray (ESpray) devices micromachined in silicon substrates. Variations to the experimental test stands from previous work demonstrating Ethanol spraying are described for the successful demonstration of JP-8 spraying. Five different ESpray devices were microfabricated to gain an understanding of the operating limits for stable electrospraying. The microfabrication of ESpray devices consists of independently fabricating its two components (extractor and nozzle array layers) with standard photolithography and deep reactive ion etching (DRIE) of silicon substrates. Precise alignment $(<2 \mu \mathrm{m})$ and assembly of silicon nozzle and extractor layers is accomplished with optical fibers embedded between the surfaces of each layer. Devices with $90 \mu \mathrm{m}$ and $75 \mu \mathrm{m}$ outer diameter (OD) nozzles showed electrospraying of Ethanol over a range of applied voltages and flow rates. Tests using JP-8 fuel with $1 \%$ Stadis 450 (to enhance electrical conductivity) showed flow rates in excess of $0.50 \mathrm{ml} / \mathrm{hr} /$ nozzle with $75 \mu \mathrm{m}$ O.D. . devices - an increase compared to Ethanol. Consequently, a continuous and stable electrospray was shown for extended periods ( $>30 \mathrm{~min}$ ) for both Ethanol and JP-8 tests.

\section{SUBJECT TERMS}

MEMS, electrospray, atomization, silicon, ethanol, JP-8

\begin{tabular}{|l|l|l|l|l|l|}
\hline \multicolumn{2}{|l|}{ 16. SECURITY CLASSIFICATION OF: } & $\begin{array}{c}\text { 17. LIMITATION } \\
\text { OF ABSTRACT } \\
\text { U. }\end{array}$ & $\begin{array}{l}\text { 18. NUMBER } \\
\text { OF PAGES } \\
\text { a. REPORT }\end{array}$ & \multirow{2}{*}{$\begin{array}{l}\text { 19a. NAME OF RESPONSIBLE PERSON } \\
\text { C. Mike Waits }\end{array}$} \\
\cline { 1 - 2 } & $\begin{array}{l}\text { b. ABSTRACT } \\
\text { Unclassified }\end{array}$ & $\begin{array}{l}\text { c. THIS PAGE } \\
\text { Unclassified }\end{array}$ & Unclassified & & $\begin{array}{l}\text { 19b. TELEPHONE NUMBER (Include area code) } \\
\text { (301) 394-0057 }\end{array}$ \\
\hline
\end{tabular}




\section{Contents}

List of Figures $\quad$ iv

List of Tables $\quad$ iv

$\begin{array}{ll}\text { 1. Introduction } & 1\end{array}$

2. Fabrication $\quad 2$

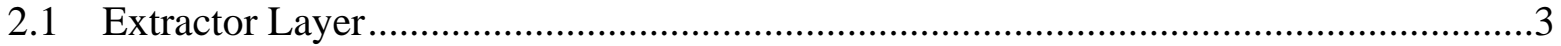

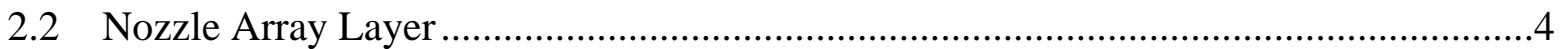

2.3 Assembly of Nozzle and Extractor Layers.............................................................5

3. Experimental Methods $\quad 6$

4. Results and Discussion $\quad 8$

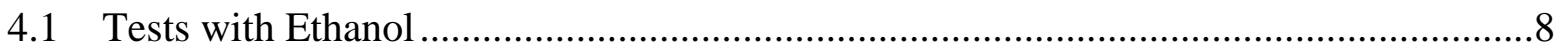

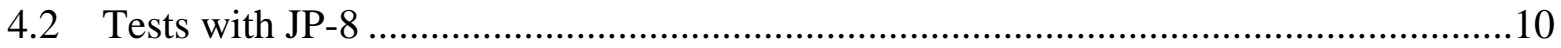

5. Summary and Conclusions $\quad 14$

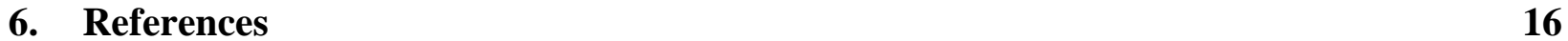

$\begin{array}{ll}\text { List of Symbols, Abbreviations, and Acronyms } & 17\end{array}$

$\begin{array}{ll}\text { Distribution List } & 18\end{array}$ 


\section{List of Figures}

Figure 1. Cross-section drawing showing the critical aspects of the ESpray device with $\mathrm{HV}_{1}$ $>\mathrm{HV}_{2}>$ gnd.

Figure 2. Geometries of devices based on design guidelines. ..................................................3

Figure 3. Fabrication process flow for the extractor layer...................................................4

Figure 4. Process flow for the fabrication of the nozzle array layer.........................................5

Figure 5. SEM image showing side view of $75 \mu \mathrm{m}$ outer diameter (O. D.) nozzles....................5

Figure 6. Extractor and nozzle layers are assembled and then attached to a plastic manifold

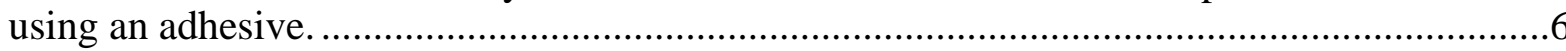

Figure 7. ESpray test setup. High voltages $\left(\mathrm{HV}_{1}\right.$ of $8 \mathrm{kV}>\mathrm{HV}_{2}$ of $\left.7 \mathrm{kV}\right)$ are applied to the nozzle and extractor layers, respectively, and a grounded mesh downstream collects the charged fluid.

Figure 8. Illuminated Ethanol spray with laser diode: (a) ESpray emitted under low flow rate (b) ESpray emitted under high flow rate when space-charge becomes a dominant effect, which is evident by the widening of the spray.....

Figure 9. SEM image of a top-view of a $90 \mu$ m outer diameter (O.D.) nozzle layer with clogged nozzle.

Figure 10. Enhancing the electrical conductivity of the JP-8 fuel by adding Stadis 450 . The conductivity for doped JP-8 was estimated for concentration of Stadis below5\%.....

Figure 11. SEM images showing a broken portion at the base of the silicon nozzle (90 $\mu \mathrm{m}$ O.D.) due to over etching......

Figure 12. SEM image of (a) fabricated nozzle before testing and (b) after several tests with JP-8 fuel, showing residue collected on the nozzle surface that may affect stability of the ESpray.

Figure 13. Illuminated JP-8 spray with red and green laser diode.

\section{List of Tables}

Table 1. Design guidelines of various devices including outer (O.D.) and inner (I.D.) diameters.

Table 2. ESpray devices, each with 19 fabricated nozzles, tested with pure Ethanol and with a grounded mesh $10 \mathrm{~mm}$ downstream of extractor layer.

Table 3. ESpray device with 19 nozzles and $75 \mu \mathrm{m}$ O. D. nozzles, tested with JP-8 + Stadis $450(1 \%)$, and $0.45 \mu \mathrm{m}$ filter membrane. Nozzle voltage $\left(\mathrm{HV}_{1}\right)$ at $8 \mathrm{kV}$, and extractor voltage $\left(\mathrm{HV}_{2}\right)$ at $7 \mathrm{kV}$, with a grounded mesh $10 \mathrm{~mm}$ downstream. 


\section{Introduction}

In recent years, the U.S. Army has increased efforts to develop compact, portable power systems that can convert logistic, high-energy density liquid fuels such as JP-8 (jet propellant) into electrical energy (1). These power converters effectively used electrospray (ESpray) technology to break up fuel into fine droplets for meso-scale combustion applications. In order to realize scaled-down power converters, smaller droplet sizes are required to completely evaporate within the effectively reduced volume (or residence time) and adequately mix with the oxidizer. Weiwei et al. demonstrated that smaller droplet sizes $(<10 \mu \mathrm{m})$ are possible, but at the expense of a lower flow rate per nozzle $(2,3)$. Thus, an increased number of jets or nozzles operating in parallel (multiplexing) is required to maintain or increase the liquid flow rate, as opposed to dispersing the liquid fuel from a single nozzle. Silicon batch microfabrication and assembly techniques have enabled compact, highly dense nozzle arrays with initial work demonstrating 250 nozzles $/ \mathrm{cm}^{2}$ (2-4), and recent work demonstrating greater than 11,500 nozzles/ $\mathrm{cm}^{2}$ (5). Further, our group has previously reported the demonstration of Ethanol in microfabricated ESpray components (5-6).

This report focuses on the assembly, experimental methods, and testing procedure to characterize JP-8 fuel atomization using the previously developed high-density device (4-6). More experimental results are also provided for Ethanol than previously reported in (6). Ultimately, these experimental procedures will determine the operation space for stable ESpray and develop an empirical model to predict the maximum sustainable flow rates (limited by space-charge effects) for various device designs. The model will also provide guidelines to determine the optimum geometry for maximizing liquid flux (flow rate per area). Consequently, this research work will be relevant to the micro-electro-mechanical-systems (MEMS)-based power components efforts that are currently being developed in the Sensors and Electrons Devices Directorate (SEDD) under the power for the dismounted Soldier Army Technology Objective (ATO).

As mentioned previously, the ESpray phenomenon effectively disperses or breaks up a liquid into smaller droplets of uniform size (figure 1). A slightly conductive liquid $\left(>10^{-8} \mathrm{~S} / \mathrm{m}\right)$, such as pure Ethanol or JP-8 fuel with a conductive additive (Stadis-450), flows through a nozzle and emerges at the tip. This liquid forms a (Taylor) cone at the nozzle tip through the balance of capillary forces and an electro hydrodynamic force from an applied potential difference between the nozzle and extractor layers $\left(\mathrm{HV}_{1}-\mathrm{HV}_{2}\right)$. When a critical electric field is reached and exceeded (due to applied voltages $\mathrm{HV}_{1}-\mathrm{HV}_{2}$ ), a thin jet of charged liquid emerges from the cone. Fluctuations at the tip of the jet disperse the droplets past the extractor layer, while Coulombic repulsive forces between the charged droplets cause them to spread into a mono-dispersed charged droplet cloud. Space-charge within the droplet cloud is a unique effect of multiplexing 
that limits the maximum flow rate of the device. As a result, space-charge effect, rather than the constraints set by the allowable droplet diameter to jet diameter for sufficient support of the Taylor cone (7), is more crucial in device performance. Shielding from charged droplets downstream (space-charge effect) can cause satellite droplets near the edge of the spray to deflect back to the extractor surface. Consequently, this may lead to flooding and, eventually, disrupt the ESpray (6). To counteract this effect, an additional electrically-grounded collector mesh is placed downstream (figure 1), so that a sufficiently large driving field, as a result of the potential difference $\left(\mathrm{HV}_{2}-\right.$ gnd), can drive or pull away the mist of charged droplets from the extractor layer.

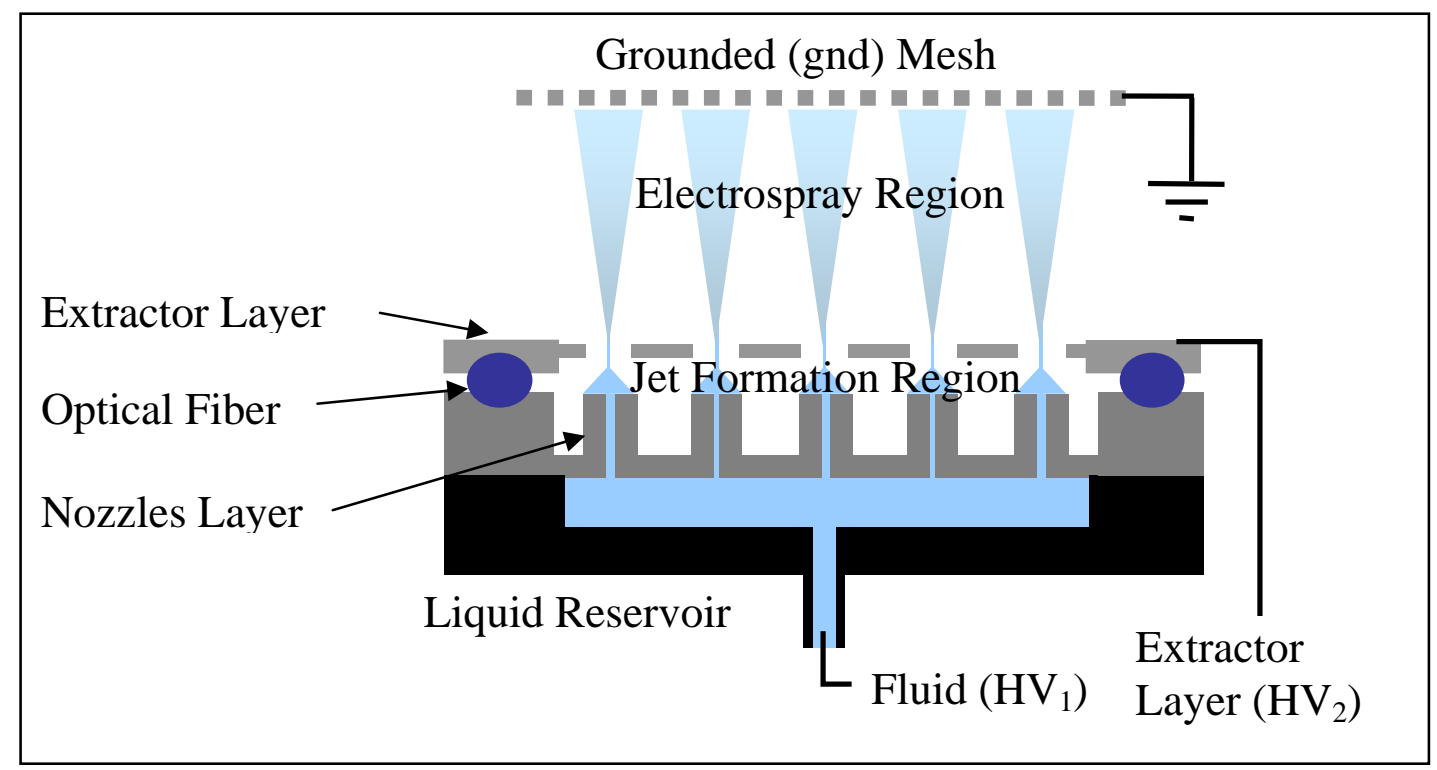

Figure 1. Cross-section drawing showing the critical aspects of the ESpray device with $\mathrm{HV}_{1}>\mathrm{HV}_{2}>$ gnd.

\section{Fabrication}

As described in references 4 and 5, the multiplexed ESpray consists of three main components: (1) extractor layer, (2) nozzle array layer, and (3) optical fibers as a spacer (figure 1). To summarize the fabrication and assembly steps, the extractor and nozzle array layers are fabricated independently in different silicon substrates using silicon micromachining (described later in detail). Then, individual chips are cut into $12.5 \mathrm{~mm} \times 12.5 \mathrm{~mm}$ die using a rotating dicing saw and assembled using optical fiber segments. The optical fiber segments (with diameter of $250 \pm 5 \mu \mathrm{m}$ ) embedded between the two silicon layers provide electrical isolation and set a specified gap (S), as depicted in figure 2. Also, a plastic manifold is attached to the backside of the nozzle layer and serves as the fluid reservoir. The plastic manifold and ESpray device are all held together by high-temperature resistant adhesives. 
Silicon micromachining allows for batch fabrication of a high density of nozzles having varying diameter, separation, or pitch, as shown in table 1. Five different designs were fabricated to create an empirical model of the space-charge effect for comparison to the line-of-charge model provided by W. Deng (8). Future work will develop this further, but in this report, the first batch of fabricated 90 and $75 \mu \mathrm{m}$ outer diameter (O.D.) devices are tested for Ethanol and JP-8 demonstration.

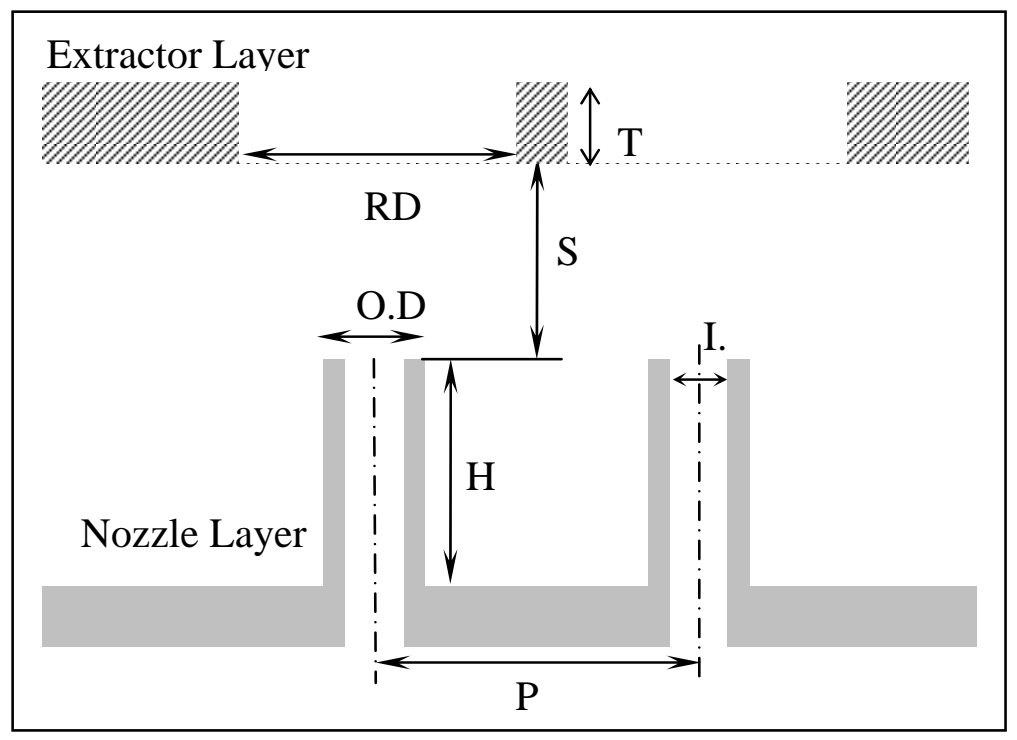

Figure 2. Geometries of devices based on design guidelines.

Table 1. Design guidelines of various devices including O.D. and inner diameter (I.D.).

\begin{tabular}{|c|c|c|c|c|c|c|}
\hline $\begin{array}{c}\text { O.D. } \\
(\mathbf{\mu m})\end{array}$ & $\begin{array}{c}\text { I.D. } \\
\mathbf{( \mu \mathbf { m } )}\end{array}$ & $\begin{array}{c}\text { Nozzle height, } \mathbf{H} \\
\mathbf{( \mu \mathbf { m } )}\end{array}$ & $\begin{array}{c}\text { Membrane, T } \\
\mathbf{( \mu \mathbf { m } )}\end{array}$ & $\begin{array}{c}\text { Gap, } \mathbf{S} \\
\mathbf{( \mu \mathbf { m } )}\end{array}$ & $\begin{array}{c}\text { Pitch, } \mathbf{P} \\
\mathbf{( \mu \mathbf { m } )}\end{array}$ & $\begin{array}{c}\text { Extractor, RD } \\
\mathbf{( \mu \mathbf { m } )}\end{array}$ \\
\hline 90 & 45 & 240 & 50 & 180 & 300 & 180 \\
\hline 75 & 38 & 200 & 50 & 150 & 250 & 150 \\
\hline 60 & 30 & 160 & 50 & 120 & 200 & 120 \\
\hline 45 & 23 & 120 & 50 & 90 & 150 & 90 \\
\hline 30 & 15 & 80 & 50 & 60 & 100 & 60 \\
\hline
\end{tabular}

\subsection{Extractor Layer}

The fabrication of the extractor layer consists of a two-mask process using a $100 \mathrm{~mm}$ diameter silicon substrate ( $200 \pm 20 \mu \mathrm{m}$ in thickness) with a $1 \mu \mathrm{m}$ thermally grown $\mathrm{SiO}_{2}$ layer (figure 3). First, the topside and bottom-side $\mathrm{SiO}_{2}$ layers are patterned to define the extractor cavity and through holes, respectively (figure 3, Step 1). Then, deep reactive ion etching (DRIE) of silicon 
is used to define the extractor holes and trenches on the bottom-side (figure 3, Step 2), and then completes the extractor by etching the cavity on the topside (figure 3, Step 3). For improved electrical contact to the extractor layer, the remaining $\mathrm{SiO}_{2}$ layer is completely removed using a 6:1 buffer oxide wet-etch (BOE) solution for $15 \mathrm{~min}$. Lastly, the silicon extractor layer is cut into individual $12.5 \mathrm{~mm} \times 12.5 \mathrm{~mm}$ die using a dicing saw.

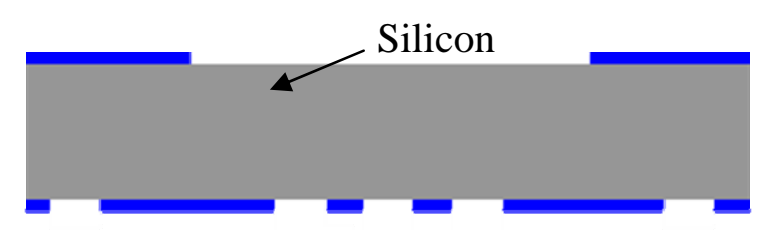

1. Pattern $\mathrm{SiO}_{2}$ on top to define cavity, and bottom for extractor holes and alignment trenches.

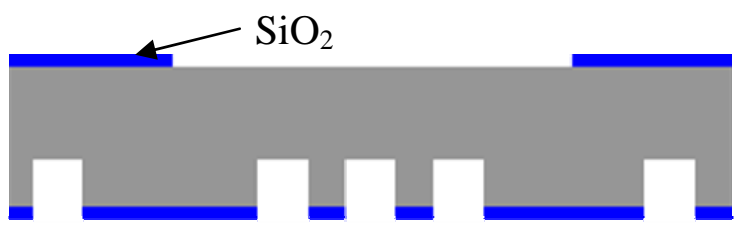

2. DRIE-etch silicon to partially define extractor holes and alignment trenches with $\mathrm{SiO}_{2}$ as mask.



3. Complete extractor membrane by DRIE-etching top silicon cavity with $\mathrm{SiO}_{2}$ as mask.

Figure 3. Fabrication process flow for the extractor layer.

\subsection{Nozzle Array Layer}

Similar to the extractor layer, the nozzle array requires a series of $\mathrm{SiO}_{2}$ patterning and silicon substrate etches ( $\sim 45 \mu \mathrm{m}$ in thickness), as shown in figure 4 . First, the nozzles and alignment trenches are patterned into the $\mathrm{SiO}_{2}$ layer (figure 4, Step 1). Then, the inner nozzle hole is patterned into a photoresist masking layer and is pre-etched using DRIE, which takes into account the difference in etch rate (RIE-lag) between the inner diameter of the holes and the surrounding open areas (figure 4, Step 2). Next, the bottom-side oxide layer is patterned and the silicon is etched using DRIE to ensure the nozzle inner hole will punch through on the next step (figure 4, Step 3). Lastly, the topside silicon is etched to define the nozzle height and optical fiber trench depth using the previously patterned $\mathrm{SiO}_{2}$ layer (figure 4, Step 4). Well-defined, sharp sidewall nozzle profiles that are required for mechanical stability are achieved by tailoring the deposition and etching times of the DRIE cycles. A specific DRIE process was designed to acquire the sharp sidewall profiles for each device design to counteract RIE-lag for each different nozzle pitch (table 1). The image from a scanning electron microscope (SEM) shows the sideview of a $75 \mu \mathrm{m}$ O.D. device (figure 5) with the sharp sidewalls obtained for $200 \mu \mathrm{m}$ tall nozzles. 




Figure 4. Process flow for the fabrication of the nozzle array layer.

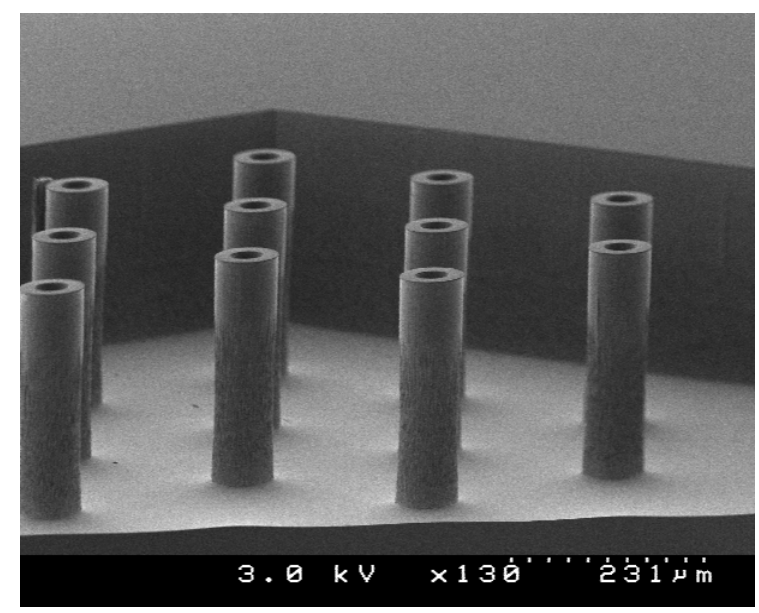

Figure 5. SEM image showing side view of $75 \mu \mathrm{m}$ O.D. nozzles.

\subsection{Assembly of Nozzle and Extractor Layers}

Once the fabrication of the individual layers is complete, optical fiber segments are positioned and fixed in the trenches around the nozzle layer with an adhesive (figure 6). Similarly, the adhesive is applied in the trenches of the extractor layer and is carefully placed (with trenches facing down) on the optical fibers. The two layers slide into place with a small applied force on the top extractor layer, allowing the nozzle to be precisely aligned with the extractor opening (RD) and have axial misalignments $<1-2 \mu \mathrm{m}$. Once the device layers are assembled, a cut plastic manifold is attached with a soft room-temperature vulcanizing (RTV) silicone sealant to the back of the nozzle layer, thus, forming a reservoir for the supplied fluid (figure 6). A stainless-steel tube is also attached to the plastic manifold to provide a feed into the reservoir. Additionally, a stainless-steel wire is wound on the inside surface of the plastic manifold and extended down through the tube. Consequently, the wire serves two purposes: (1) to enhance 
electrification of the fluid and (2) to reduce the cross-sectional area of the tube to minimize bubble formation.

Moreover, it is critical to choose a proper adhesive for the assembly of the device to ensure good mechanical strength for handling and testing of the ESpray device. However, we found that separation of the layers was necessary for inspection and cleaning of the device when using JP-8. Previous work with Ethanol did not require layer separation and, therefore, a hard epoxy was used with excellent mechanical properties (Loctite E-20HP). On the other hand, using the epoxy on devices tested with JP-8 made them difficult to re-assemble because the epoxy cannot be completely removed out of the trenches. Additionally, the epoxy had a relatively low temperature of operation (up to $\sim 200^{\circ} \mathrm{C}$ ). Instead, a soft RTV silicone sealant was used in this work to assemble the layers and allow for easy removal and cleaning. Once the silicone is cured at ambient temperature for $24 \mathrm{~h}$, it provides sufficient bonding strength to keep the layers together and can operate at temperatures $>20{ }^{\circ} \mathrm{C}$. In contrast to the epoxy, the silicone becomes soft by being immersed in solvent such as acetone for two days, and can be easily removed from the silicon surface or trenches.

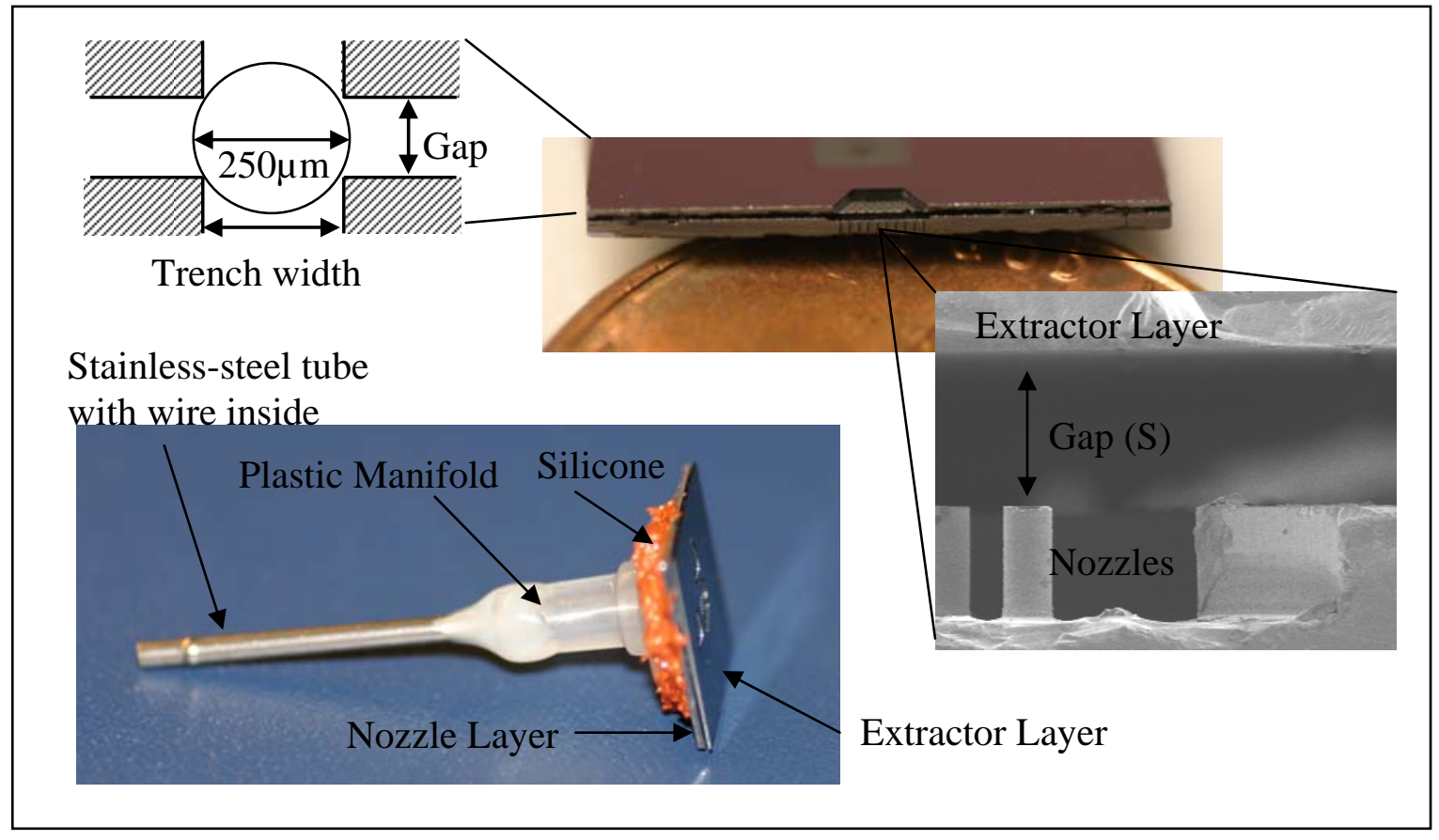

Figure 6. Extractor and nozzle layers are assembled and then attached to a plastic manifold using an adhesive.

\section{Experimental Methods}

The assembled ESpray device is fixed on a horizontal Teflon rod and electrical contacts are made to the device. Specifically, a high voltage $\left(\mathrm{HV}_{1}\right)$ of $8 \mathrm{kV}$ is applied to the stainless-steel feeding tube that is in direct contact with the Ethanol or JP-8 fuel while a lower voltage $\left(\mathrm{HV}_{2}\right)$ of 
$7 \mathrm{kV}$ is applied on the surface of the extractor via a bent conducting wire (figure 7). As a result, a $\Delta V=1 \mathrm{kV}$ potential difference is maintained between the nozzle array and extractor layers. An electrically grounded stainless-steel mesh placed $10 \mathrm{~mm}$ downstream collects and neutralizes the charged particles within the spray.

After the voltages are applied, the desired flow rate is set using a mechanical syringe pump. The fluid (Ethanol or JP-8) is first passed through a filter prior to being dispensed into the device. Previously, a $1 \mu \mathrm{m}$ filter was used in the Ethanol experiments. However, since JP-8 is not as well-filtered as pure Ethanol, a $0.45 \mu \mathrm{m}$ was used to ensure minimal particle build-up in the nozzles. Residue build-up on the nozzle tip might affect stable ESpray since it may disrupt a proper formation of the Taylor cone on the tip and the emerging jet. Furthermore, different tubing sets were used to prevent contamination or mixing between different fluids; for instance, one set was used for JP-8 tests and another for Ethanol tests. Also, different tubing sets were used for various concentrations of JP-8 and Stadis 450 solutions.

Additionally, electrical short-circuit of the extractor and nozzle layers can occur when the conducting fluid floods the two layers. Thus, over-voltage damage can be done to the lower voltage supply. To prevent this issue, a high-voltage protection diode (in this work up to $8 \mathrm{kV}$ ) was added to the output of each supply. Furthermore, a Laser diode module allowed visualization of the fluid spray dispersing away from the extractor layer, while a video-camera system recorded the emerging spray (figure 7). A future testing apparatus will include a Phase Doppler anemometry (PDA) system, rather than a Laser diode, for improved imaging of the droplet cloud and direct measurement of the droplet diameters and velocity distribution. 


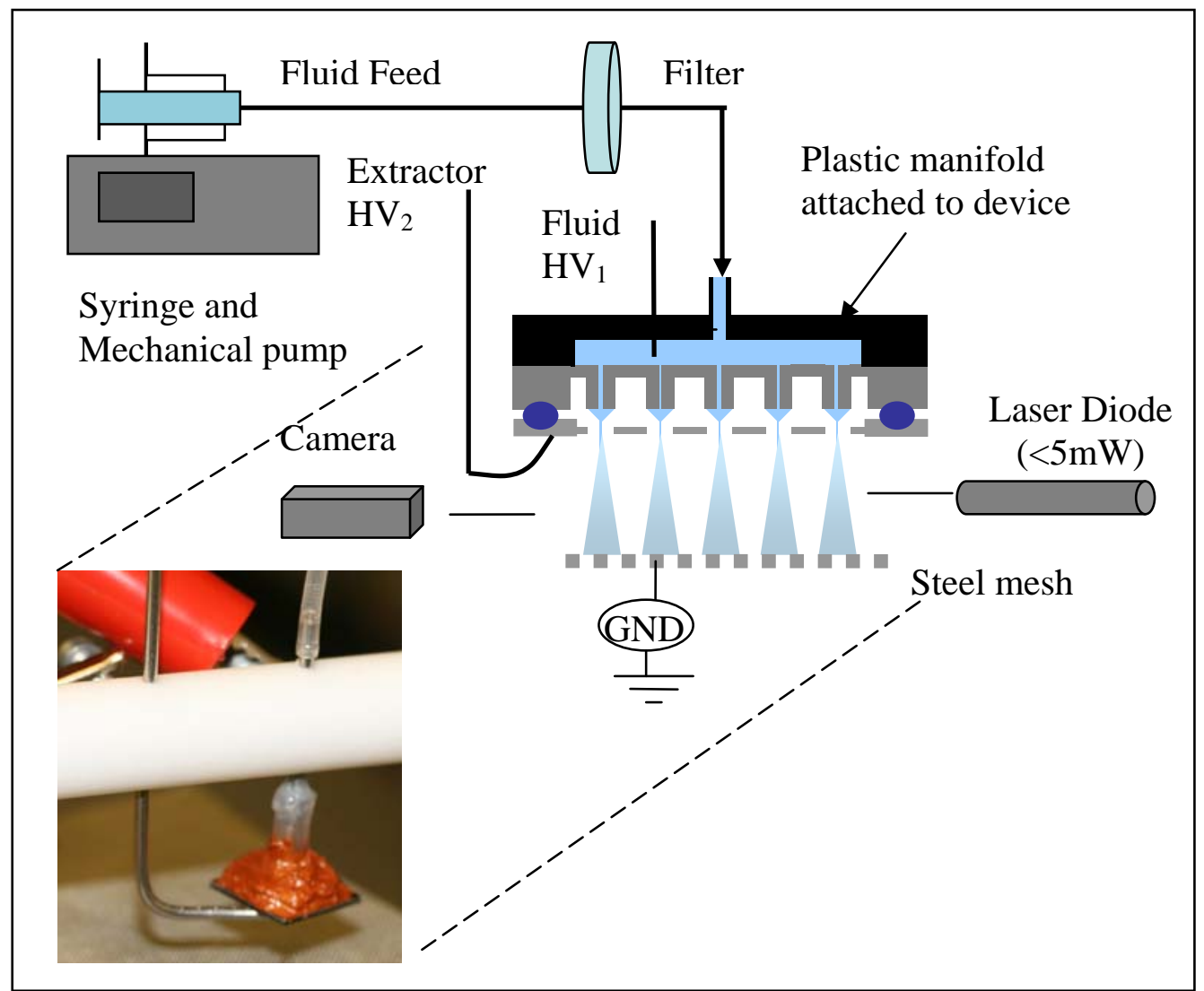

Figure 7. ESpray test setup. High voltages $\left(\mathrm{HV}_{1}\right.$ of $8 \mathrm{kV}>\mathrm{HV}_{2}$ of $\left.7 \mathrm{kV}\right)$ are applied to the nozzle and extractor layers, respectively, and a grounded mesh downstream collects the charged fluid.

\section{Results and Discussion}

\subsection{Tests with Ethanol}

The values of the nozzle voltage $\left(\mathrm{HV}_{1}\right)$, extractor voltage $\left(\mathrm{HV}_{2}\right)$, and flow rate were varied to determine stable regions of ESpray, and to gain an understanding of the space-charge effects (table 2). Space-charge was observed to limit the maximum flow rate that is sustained for a given device and was apparent by varying $\mathrm{HV}_{2}$ - gnd. This effect was evident by a drastic widening of the spray and liquid buildup on the extractor layer, which eventually led to flooding (figure 8b). The maximum flow rate that can be sustained for stable spray decreases as driving electric field between the extractor layer and grounded mesh decreases. We observed this when the extractor voltage decreased from $7 \mathrm{kV}$ to $3 \mathrm{kV}$, corresponding to a drop on the maximum achievable flow rate from $8 \mathrm{~mL} / \mathrm{h}$ to $1 \mathrm{~mL} / \mathrm{h}$; respectively. 
Table 2. ESpray devices, each with 19 fabricated nozzles, tested with pure Ethanol and with a grounded mesh 10 mm downstream of extractor layer.

\begin{tabular}{|c|c|c|c|c|c|}
\hline $\begin{array}{c}\text { Device } \\
\text { O.D. }(\mu \mathrm{m})\end{array}$ & $\begin{array}{c}\text { Nozzle } \\
\text { Voltage } \\
(\mathrm{kV})\end{array}$ & $\begin{array}{c}\text { Extractor } \\
\text { Voltage } \\
(\mathrm{kV})\end{array}$ & $\begin{array}{c}\text { Flow Rate } \\
(\mathrm{ml} / \mathrm{r})\end{array}$ & $\begin{array}{l}\text { Number of } \\
\text { Nozzles “on” }\end{array}$ & Observations \\
\hline 90 & 8 & 7 & $1-9$ & 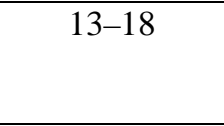 & $\begin{array}{c}\text { Stable spray that widens with increasing } \\
\text { flow rate. Device has } 1-3 \text { partially } \\
\text { clogged nozzles. }\end{array}$ \\
\hline 90 & 8 & 7 & $\geq 9$ & - & Flooding on extractor surface \\
\hline 75 & 8 & 7 & 1 & $10-11$ & 1 clogged nozzle, stable spray \\
\hline 75 & 8 & 7 & $2-6$ & $16-17$ & Stable spray \\
\hline 75 & 8 & 7 & $\geq 7$ & - & Flooded on extractor surface \\
\hline 90 & 6 & 5 & $1-3$ & $14-18$ & $\begin{array}{l}\text { Stable spray that widens with increasing } \\
\text { flow rate. Device has 1-3 partially } \\
\text { clogged nozzles. }\end{array}$ \\
\hline 90 & 6 & 5 & $\geq 4$ & $14-16$ & Flooding on extractor surface \\
\hline 90 & 4 & 3 & 1 & $12-14$ & $\begin{array}{l}\text { Stable spray that widens with increasing } \\
\text { flow rate. Device has } 1-3 \text { partially } \\
\text { clogged nozzles. }\end{array}$ \\
\hline 90 & 4 & 3 & $\geq 2$ & - & Flooding on extractor surface \\
\hline
\end{tabular}

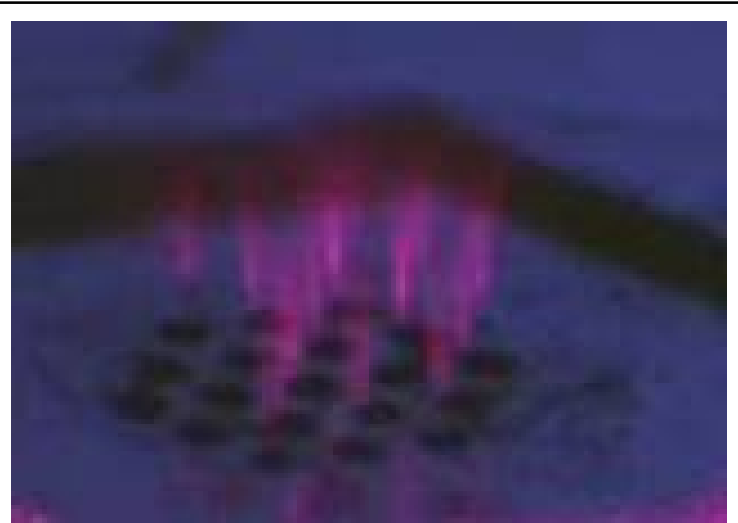

(a)

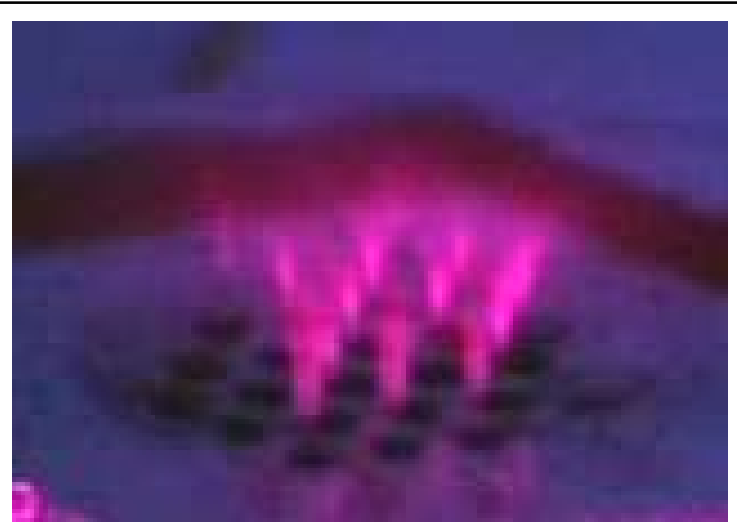

(b)

Figure 8. Illuminated Ethanol spray with laser diode: (a) ESpray emitted under low flow rate (b) ESpray emitted under high flow rate when space-charge becomes a dominant effect, which is evident by the widening of the spray.

In addition to liquid build-up on the extractor, the variation in the number of nozzles issuing a spray or that are "on" was observed to vary, and is possibly due to small bubbles inside the line being trapped within the fluid reservoir (plastic manifold). Also, partially or fully clogged nozzles resulting from insufficient silicon etching during fabrication reduced the number of nozzles issuing a spray, as well (figure 9). 


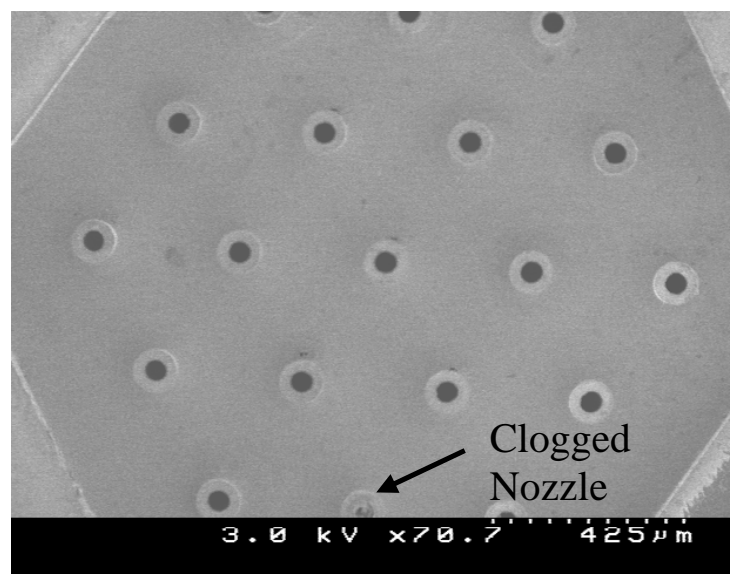

Figure 9. SEM image of a top-view of a $90 \mu \mathrm{m}$ O.D. nozzle layer with clogged nozzle.

In summary, preliminary tests with pure Ethanol indicated that flow rates in excess of $0.5 \mathrm{ml} / \mathrm{h} /$ nozzle and $0.35 \mathrm{ml} / \mathrm{h} /$ nozzle can be achieved for 19-nozzle devices having nozzle O.D.s of $90 \mu \mathrm{m}$ and $75 \mu \mathrm{m}$, respectively (table 2) (6). Moreover, ESpray with Ethanol was also observed for potential differences $\left(\mathrm{HV}_{2}-\mathrm{HV}_{1}\right)$ ranging from $0.5-2 \mathrm{kV}$ and flow rates from $0.5-$ $10 \mathrm{ml} / \mathrm{h}$. Similarly, these devices showed a sustained and continuous ESpray for extended periods (>30 min) (figure $8 a$ ).

\subsection{Tests with JP-8}

The experiments with JP-8 fuel also followed a similar procedure as those with Ethanol, with a main difference being the addition of an electrostatic additive (Stadis 450) to JP-8. The purpose of the additive is to increase the electrical conductivity, thus enabling easier electrification of the fluid. Since the minimum measurable conductivity for the meter used (Oakton series 400 ) is $\sim 1$ $\times 10^{-8} \mathrm{~S} / \mathrm{m}$, or $1 / \Omega \mathrm{m}$, the value was estimated from the experimentally obtained curve in figure 10. In comparison, the electrical conductivity of Ethanol, measured with the same meter, ranged from $\sim 30 \times 10^{-8}-40 \times 10^{-8} \mathrm{~S} / \mathrm{m}$.

First, solutions of Stadis 450 added to JP-8 yield concentrations of $0.3 \%$ and $1 \%$ by volume were prepared. Testing with these solutions intially showed brief periods of ESpray ( $<10 \mathrm{~min}$.) with an on/off flickering behavior, and with 5-14 nozzles “on”. Flow rates were varied from 1-4 $\mathrm{ml} / \mathrm{h}$, with applied nozzle and extractor voltages at 8 and $7 \mathrm{kV}$, respectively. The grounded mesh was also set to $10 \mathrm{~mm}$ downstream as in previous experiments. Additionally, fluid droplets were observed to form between the extractor and nozzle array layers until flooding occurred between the layers, which suggested weak support of the Taylor cone on the nozzle tip or leakage in the nozzle layer. 


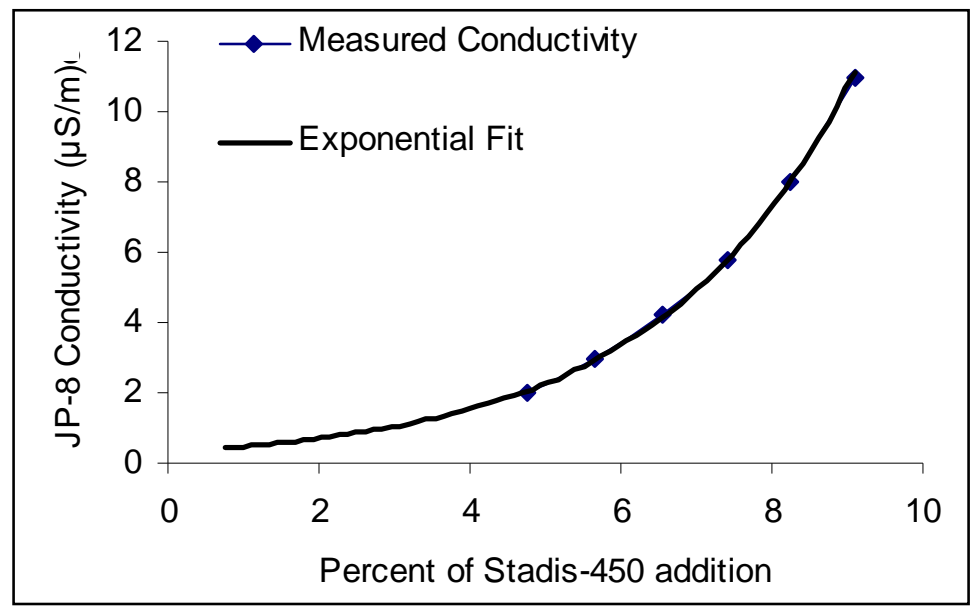

Figure 10. Enhancing the electrical conductivity of the JP-8 fuel by adding Stadis 450. The conductivity for doped JP-8 was estimated for concentration of Stadis below 5\%.

Consequently, the two layers were taken apart by softening the RTV silicone in acetone, and were carefully inspected with an SEM. One of the devices showed partially broken silicon nozzles, as shown in figure 11, while another device showed residue build-up, as depicted in figure 12b. Thus, a new device was used along with a $0.45 \mu \mathrm{m}$ filter to minimize residue buildup, which resulted this time in a stable ESpray (figure 13). Additionally, the ESpray was sustained for extended periods ( $>30 \mathrm{~min}$ ) for the various flow rates tested $(1-8 \mathrm{ml} / \mathrm{h})$, as shown on table 3.

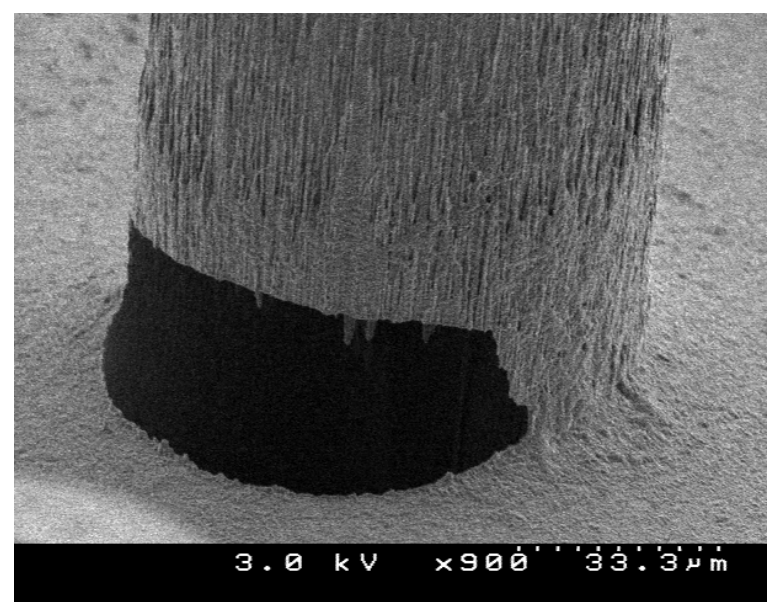

Figure 11. SEM images showing a broken portion at the base of the silicon nozzle ( $90 \mu \mathrm{m}$ O.D.) due to over etching. 


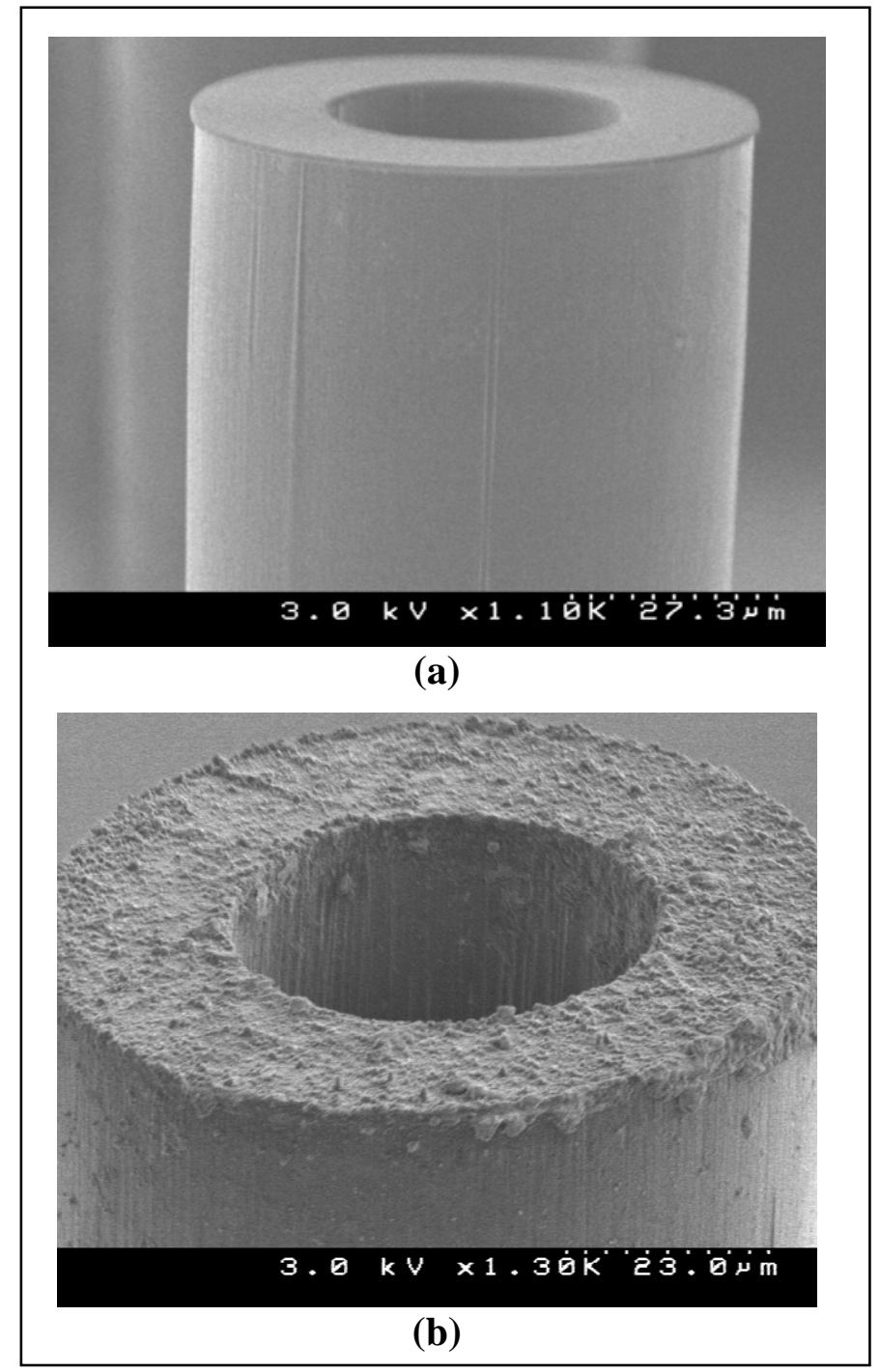

Figure 12. SEM image of (a) fabricated nozzle before testing and (b) after several tests with JP-8 fuel, showing residue collected on the nozzle surface that may affect stability of the ESpray. 


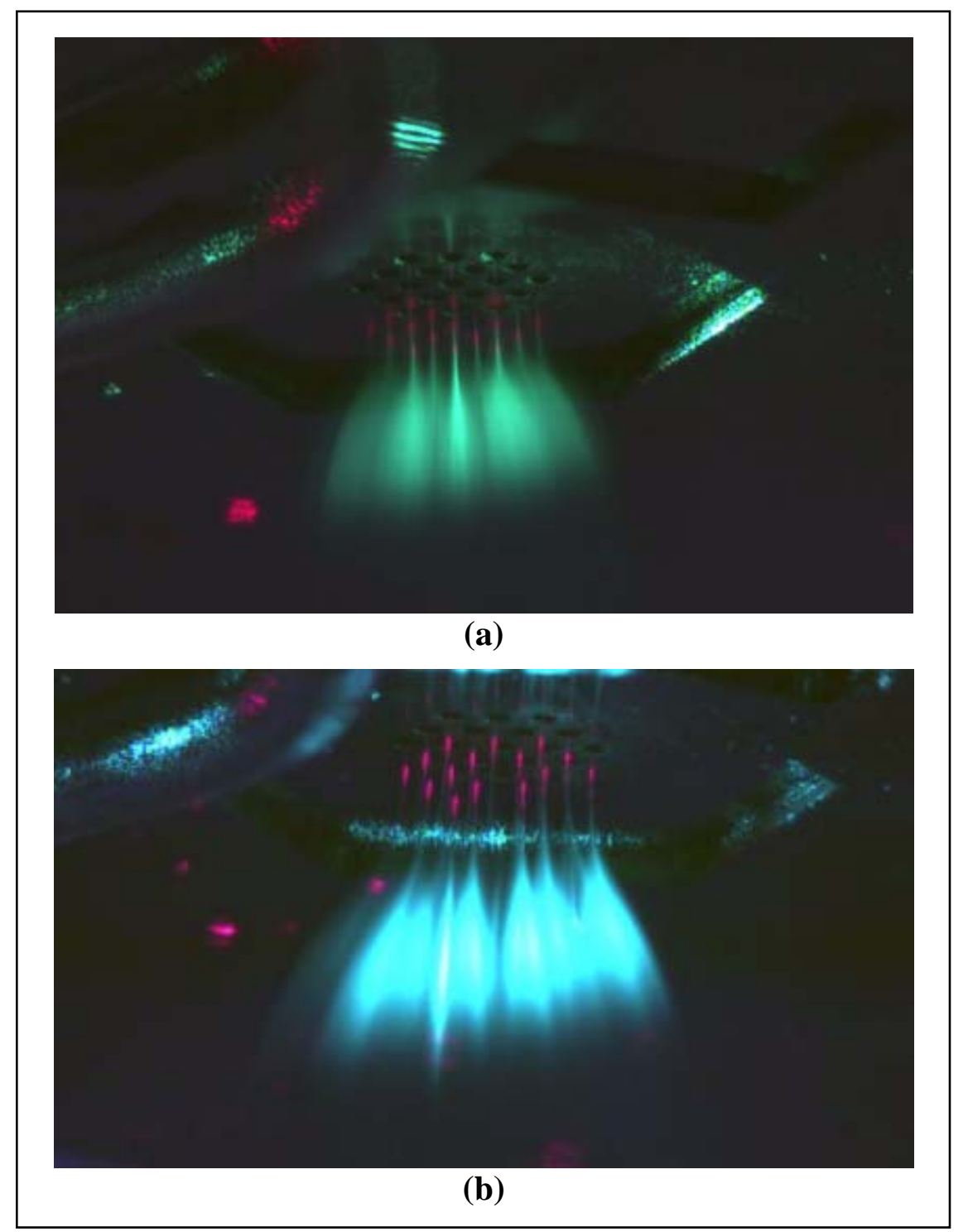

Figure 13. Illuminated JP-8 spray with red and green laser diode.

Table 3. ESpray device with 19 nozzles and $75 \mu$ m O.D. nozzles, tested with JP-8 + Stadis 450 (1\%), and $0.45 \mu \mathrm{m}$ filter membrane. Nozzle voltage $\left(\mathrm{HV}_{1}\right)$ at $8 \mathrm{kV}$, and extractor voltage $\left(\mathrm{HV}_{2}\right)$ at $7 \mathrm{kV}$, with a grounded mesh $10 \mathrm{~mm}$ downstream.

\begin{tabular}{|c|c|c|c|c|c|}
\hline $\begin{array}{c}\text { Device } \\
\text { O.D. }(\boldsymbol{\mu m})\end{array}$ & $\begin{array}{c}\text { Nozzle } \\
\text { Voltage } \\
\mathbf{( k V )}\end{array}$ & $\begin{array}{c}\text { Extractor } \\
\text { Voltage } \\
\mathbf{( k V )}\end{array}$ & $\begin{array}{c}\text { Flow Rate } \\
\mathbf{( m \mathbf { l } / \mathbf { h } )}\end{array}$ & $\begin{array}{c}\text { Number of } \\
\text { Nozzles “On” }\end{array}$ & Observations \\
\hline 75 & 8 & 7 & $1-3$ & $11-17$ & Stable spray \\
\hline 75 & 8 & 7 & $3.5-4.5$ & $8-9$ & Stable spray \\
\hline 75 & 8 & 7 & $5-7$ & $9-17$ & Stable spray \\
\hline 75 & 8 & 7 & $7.5-8$ & 17 & Stable, widening spray \\
\hline
\end{tabular}


The variation in the number of nozzles "on" may be due to small air bubbles trapped in the fluid reservoir, which may cause only some nozzles to issue a spray. Thus, it is important to flush out any visible bubbles trapped within the feeding lines prior to testing. Overall, tests with JP-8 fuel with $1 \%$ Stadis 450 showed flow rates in excess of $0.5 \mathrm{ml} / \mathrm{h} /$ nozzle with the $75 \mu \mathrm{m}$ O.D. device, with more nozzles "on" at the higher flow rates $(\sim 8 \mathrm{ml} / \mathrm{h})$, as shown on table 3 . The lower flow rates $(<7 \mathrm{ml} / \mathrm{h})$ showed more variation in the number of nozzles 'on' due to trapped bubbles in the reservoir. Similarly, sustained and prolonged periods of ESpray were also demonstrated with characteristic spray shown in figure 13. As mentioned previously, future tests will focus on determining and extending the maximum flow rates that each ESpray design can sustain.

These preliminary results suggest that the space-charge effect is reduced for JP-8 compared to Ethanol. We reached this conclusion by observing the increased maximum flow rate per nozzle of $0.5 \mathrm{~mL} / \mathrm{h} /$ nozzle for the $75 \mu \mathrm{m}$ O.D. spray with JP-8, as compared to $0.35 \mathrm{~mL} / \mathrm{h} / \mathrm{nozzle}$ achieved when spraying Ethanol. Furthermore, the increase in flow rate may result from the lower conductivity and higher surface tension of JP-8, which may cause an effective lower droplet surface charge density than the droplets formed with Ethanol, therefore reducing the Coulomb repulsion force among droplets downstream. Further characterization will enable the development of an empirical model for both JP-8 and Ethanol to corroborate the analytical model developed by Weiwei et al. (7).

\section{Summary and Conclusions}

This work has shown the microfabrication method and improvements in the experimental test procedure to demonstrate multiplexed ESpray devices using Ethanol and JP-8 fuel. The extractor and nozzle array layers are independently micromachined in separate silicon substrates, which allow for batch fabrication of compact, small-scale fuel atomization devices for portable power applications. The individual layers are then assembled using an RTV silicone sealant that provides strong bonding between the layers and allows easy removal of the layers for inspection and cleaning, which is important for JP-8 testing. The devices are tested using pure Ethanol and JP-8 fuel with Stadis 450 to determine the voltages and flow rates required for stable operation. ESpray was demonstrated for voltage differences (between nozzle and extractor) from $\sim 0.5-2 \mathrm{kV}$ and flow rates from $\sim 0.5-10 \mathrm{ml} / \mathrm{h}$. Preliminary tests with Ethanol indicated that flow rates $>0.5$ $\mathrm{ml} / \mathrm{h} /$ nozzle and $0.35 \mathrm{ml} / \mathrm{h} /$ nozzle can be achieved for tested devices with $90 \mu \mathrm{m}$ and $75 \mu \mathrm{m}$ O.D., respectively. Above these flow rates, flooding of the extractor layer was observed due to space-charge interaction between the charged droplets downstream. Also, flow rates in excess of $0.5 \mathrm{ml} / \mathrm{h} /$ nozzle can be achieved with JP-8 using a $75 \mu \mathrm{m}$ O.D. device, which is an increase over Ethanol spraying. Moreover, stable and continuous ESpray for extended periods ( $>30 \mathrm{~min}$ ) was demonstrated for both Ethanol and JP-8 fuel. 
Preliminary tests with Ethanol and JP-8 resulted in identifying a stable regime for ESpray, which serves as a preliminary guideline for ongoing work. Future efforts will further investigate spacecharge effects and extend the flow rates of these devices with Ethanol and the logistics fuel JP-8. In addition to varying the applied voltages, another improvement includes providing a tail air flow to the charged droplets to limit build-up on the extractor surface. Lastly, integrating these MEMS-based ESpray devices with a JP-8 catalytic combustion system, for instance, is an application that will be also investigated. 


\section{References}

1. Huth, J.; Ezekiel, H.; Buffalino, A.; Gomez, A.; Roychoudhury, S. SunPower, Inc., http://www.precision-combustion.com/HP-08.pdf 1-5, 2006.

2. Deng, W.; Klemic, J. F.; Li, X.; Reed, M. A.; Gomez, A. Proceedings of the Combustion Institute, 31, 2239-2246, 2007.

3. Dent, W.; Klemic, J. F.; Li, X.; Reed, M. A.; Gomez, A. Journal of Aerosol Science 2006, 37, 696-714.

4. Waits, C. M.; Jankowski, N.; Geil, B. Scalable Electrospray Components for Portable Power Application Using MEMS Fabrication Techniques. $25^{\text {th }}$ Army Science Conference, Orlando, FL, Nov. 27-30, 2006.

5. Waits, C. M.; Morgan, B.; Deng, W.; Jankowski, N. R.; Gomez, A.; Geil, B. Solid-State Sensors, Actuators, and Microsystems Workshop (Hilton Head Conference), June 1-5, 220223, 2008.

6. Boniche, I.; et al. ARL Summer Student Research Symposium; ARL-TM-2008; U.S. Army Research Laboratory: Adelphi, MD, 107-119, August, 2008.

7. Deng, W.; Gomez, A. Influence of space charge on the scale-up of multiplexed electrosprays. Journal of Aerosol Science 2008, 38, 1062-1078.

8. Deng, W. Ph.D. Dissertation, Yale University, 57-87, 2008. 


\section{List of Symbols, Abbreviations, and Acronyms}

$\begin{array}{ll}\text { ATO } & \text { Army Technology Objective } \\ \text { BOE } & \text { buffered-oxide etch } \\ \text { DRIE } & \text { deep reactive ion etching } \\ \text { ESpray } & \text { electrospray } \\ \text { HV } & \text { high voltage } \\ \text { I.D. } & \text { inner diameter } \\ \text { JP } & \text { jet propellant } \\ \text { MEMS } & \text { micro-electro-mechanical systems } \\ \text { O.D. } & \text { outer diameter } \\ \text { PDA } & \text { phase Doppler anemometry } \\ \text { RTV } & \text { room-temperature vulcanizing } \\ \text { SEDD } & \text { Sensors and Electron Devices Directorate } \\ \text { SEM } & \text { scanning electron microscope }\end{array}$


No. of

Copies Organization

1 ADMNSTR

ELECT DEFNS TECHL INFO CTR

ATTN DTIC OCP

8725 JOHN J KINGMAN RD STE 0944

FT BELVOIR VA 22060-6218

1 DARPA

ATTN IXO S WELBY

3701 N FAIRFAX DR

ARLINGTON VA 22203-1714

1 CD OFC OF THE SECY OF DEFNS

ATTN ODDRE (R\&AT)

THE PENTAGON

WASHINGTON DC 20301-3080

1

US ARMY RSRCH DEV AND ENGRG

CMND

ARMAMENT RSRCH DEV AND

ENGRG CTR

ARMAMENT ENGRG AND TECHNLGY

CTR

ATTN AMSRD AAR AEF T J MATTS

BLDG 305

ABERDEEN PROVING GROUND MD

21005-5001

1

PM TIMS, PROFILER (MMS-P)

AN/TMQ-52

ATTN B GRIFFIES

BUILDING 563

FT MONMOUTH NJ 07703

1 US ARMY INFO SYS ENGRG CMND

ATTN AMSEL IE TD F JENIA

FT HUACHUCA AZ 85613-5300

1 COMMANDER

US ARMY RDECOM

ATTN AMSRD AMR W C MCCORKLE

5400 FOWLER RD

REDSTONE ARSENAL AL 35898-5000

1 US GOVERNMENT PRINT OFF

DEPOSITORY RECEIVING SECTION

ATTN MAIL STOP IDAD J TATE

732 NORTH CAPITOL ST NW

WASHINGTON DC 20402
No. of

Copies Organization

1 US ARMY RSRCH LAB

ATTN AMSRD ARL CI OK TP TECHL

LIB T LANDFRIED

BLDG 4600

ABERDEEN PROVING GROUND MD

21005-5066

1 DIRECTOR

US ARMY RSRCH LAB

ATTN AMSRD ARL RO EV W D BACH

PO BOX 12211

RESEARCH TRIANGLE PARK NC 27709

12 US ARMY RSRCH LAB

ATTN AMSRD ARL CI OK PE TECHL PUB

ATTN AMSRD ARL CI OK TL TECH

LIB

ATTN AMSRD ARL SE D E SHAFFER

ATTN AMSRD ARL SE DP B GEIL

ATTN AMSRD ARL SE DP

B HANRAHAN

ATTN AMSRD ARL SE DP B MORGAN

ATTN AMSRD ARL SE DP

C M WAITS (2 COPIES)

ATTN AMSRD ARL SE DP D SHARAR

ATTN AMSRD ARL SE DP I LEE

ATTN AMSRD ARL SE DP J HOPKINS

ATTN AMSRD ARL SE DP

$\mathrm{N}$ JANKOWSKI

ATTN IMNE ALC HRR MAIL \& RECORDS MGMT

ADELPHI MD 20783-1197

Total: 22 (20 HCs, 1 CD, 1 ELECT) 